\title{
A novel lumazine synthase molecule from Brucella significantly promotes the immune-stimulation effects of antigenic protein
}

\author{
Z.Q. Du and J.Y. Wang \\ The Institute of Bioengineering and Technology, Inner Mongolia University of \\ Science and Technology, Baotou, Inner Mongolia Autonomous Region, China \\ Corresponding author: Z.Q. Du \\ E-mail: nmdzq1981@163.com
}

Genet. Mol. Res. 14 (4): 13084-13095 (2015)

Received June 9, 2015

Accepted September 1, 2015

Published October 26, 2015

DOI http://dx.doi.org/10.4238/2015.October.26.4

\begin{abstract}
Brucella, an intracellular parasite that infects some livestock and humans, can damage or destroy the reproductive system of livestock. The syndrome is referred to as brucellosis and often occurs in pastoral areas; it is contagious from livestock to humans. In this study, the intact Brucella suis outer membrane protein 31 (omp31) gene was cloned, recombinantly expressed, and examined as a subunit vaccine candidate. The intact Brucella lumazine synthase (b/s) gene was cloned and recombinantly expressed to study polymerization function in vitro. Non-reducing gel electrophoresis showed that $r B s-B L S$ existed in different forms in vitro, including as a dimer and a pentamer. An enzyme-linked immunosorbent assay result showed that rOmp31 protein could induce production of an antibody in rabbits. However, the rOmp31-BLS fusion protein could elicit a much higher antibody titer in rabbits; this construct involved fusion of the Omp31 molecule with the BLS molecule. Our results indicate that Omp31 is involved in immune stimulation, while BLS has a polymerizing function based on rOmp31-BLS fusion protein immunogenicity. These data
\end{abstract}


suggest that Omp31 is an ideal subunit vaccine candidate and that the BLS molecule is a favorable transport vector for antigenic proteins.

Key words: Brucella; Immunogenicity; Lumazine synthase enzyme gene; Outer membrane proteins; Subunit vaccine candidate

\section{INTRODUCTION}

Brucellosis is one of the world's major zoonoses and is a highly contagious bacterial disease induced by Brucella, an intracellular parasite. Once livestock are infected by Brucella, the reproductive system is damaged, resulting in concomitant loss in productivity of affected animals (Miraglia et al., 2013), causing large economic losses. Additionally, Brucella infection is a serious threat to human health and wildlife populations. Animals and their food products are the primary source of human infection; mucosal routes are the most common modes of transmission through inhalation and ingestion of animal-derived contaminated materials, respectively. Brucellosis is one of the most common zoonotic diseases, with an estimated annual incidence of 500,000 cases (Avila-Calderón et al., 2013). The situation is particularly severe in underdeveloped countries.

Brucella has been found in various animals, including cow, goat, dog, and pig, among others. Current research has shown that the genus Brucella includes at least 12 species, which are identified and divided according to host specificity and the ability to cause chronic infections in animals and humans (Muñoz et al., 2006). The 12 species of genus Brucella are Brucella abortus, B. melitensis, B. suis, B. ovis, B. canis, B. neotomae, B. microti, B. inopinata, B. pinnipedialis, B. ceti, and 2 additional species (nonhuman primates Brucella and foxes Brucella) (Godfroid et al., 2010). Notably, B. abortus, B. melitensis, and $B$. suis are responsibly for infection in animals and humans. Most Brucella species are associated primarily with specific hosts, possibly because of evolutionary adaptation. For instance, $B$. canis is the causative agent of canine brucellosis, which results in contagious abortion, uveitis, and orchiepididymitis. However, B. canis rarely causes human brucellosis (Chen et al., 2014). Transmission to humans occurs only through close contact with infected animals or bacterial cultures. B. melitensis mainly affects goats and sheep but can also infect cattle and cause severe placentitis. $B$. abortus is the most widespread, causing abortion in cattle and chronic infection in humans. $B$. suis infects a broad range of animals, including swine, reindeer, caribou, hares, various murine species, and, occasionally, cattle and dogs (Dean et al., 2012). Additionally, a different genus of Brucella may also infect different animals or humans. Although each species exhibit host preference, cross-species infections frequently occur. For example, B. canis mostly infects dogs but can also infect cattle (Yüksekkaya et al., 2013). B. melitensis is mostly limited to goats but can also infect swine (Mermer et al., 2013).

At the beginning of 20th century, studies attempted to identify a Brucella vaccine to prevent brucellosis in animals and humans (Cassataro et al., 2005a). For the prevention and control of brucellosis, live vaccines remain the main strategy examined. Nevertheless, modified live vaccines have been shown to possess superior protective immunogenic activity (Schurig et al., 2002). For instance, previously developed live vaccines included the attenuated live vaccine $B$. suis strain 2, B. abortus strain 104-M, and B. abortus VA 19. Subsequently, some killed vaccines were developed to protect against brucellosis, including $B$. abortus strain $45 / 20$ and $B$. melitensis H38. Currently, the modified live vaccines licensed for use include $B$. abortus strain $19, B$. abortus RB51, and B. melitensis Rev. 1 (Yang et al., 2013). Although these live and modified live vaccines 
are available for livestock to prevent brucellosis, their immunization programs must be maintained to limit human infection (Denisov et al., 2010). Previous studies have shown that vaccination of uninfected animals and some infected animals successfully eradicated brucellosis. However, there is no vaccine for humans, and thus animal vaccination remains a critical factor for the control and eradication of brucellosis in animals and humans. However, with the use of live vaccines in livestock, Brucella toxicity reversion often occurs (Gomez et al., 2013). Additionally, because live vaccines may cause infection in humans and resistance to antibiotics used to treat brucellosis may develop, and thus health officials have prohibited their use in human vaccination. Thus, better vaccines for livestock and humans should be developed to overcome these limitations. There is increasing interest in the immunogenicity and protective effects of Brucella outer membrane proteins (OMPs) and cytoplasmic proteins (Pollak et al., 2012). The subunit vaccines mainly include recombinant proteins, vectored vaccines, DNA vaccines, and outer membrane vesicles, among others (Cassataro et al., 2005b). Subunit vaccines are preferred over the use of the live-attenuated vaccines because live vaccines may revert to a virulent state, cause abortion in pregnant animals, and become dispersed in milk.

Bacterial cell surface proteins antigens are good vaccine candidates because they represent the initial contact point between the pathogen and host. Numerous subunit fractions from Brucella have been examined as recombinant proteins as vaccines in a mouse model, and some have shown good protective effects (Kaushik et al., 2010). Some Brucella immunogenic antigens are located on the outer membrane of this gram-negative pathogen. These proteins include Omp31, Omp28, and Omp25, among others. Omp31 molecule is regarded to be a superior recombinant protein candidate for subunit vaccine and originated from Brucella. Omp31 elicited different immune responses to protect the host against $B$. ovis in BALB/c mice and rams (Luo et al., 2006). Additionally, the Brucella lumazine synthase (BLS) enzyme is a highly immunogenic protein that functions as a decameric protein (Estein et al., 2009). When a foreign antigenic protein was covalently attached to BLS molecules, the protein's immune-stimulation effect greatly increased (Clausse et al., 2013).

In this study, we used the Brucella BLS intact molecule and Omp31 intact molecule to examine 2 questions. We examined whether the Brucella BLS intact molecule possessed polymerization function by using a reformative non-reducing sodium dodecyl sulfatepolyacrylamide gel electrophoresis (SDS-PAGE) method. Additionally, we determined whether the fusion protein molecule (Omp31-BLS) possessed superior immunogenicity compared to the Omp31 molecule by using western blotting and enzyme-linked immunosorbent assay (ELISA) techniques.

\section{MATERIAL AND METHODS}

\section{Bacterial culture}

B. suis $\mathrm{S} 2$ was grown overnight in $10 \mathrm{~mL}$ tryptic soy broth with constant agitation at $37^{\circ} \mathrm{C}$ for $16 \mathrm{~h}$. Bacterial sediment was collected by centrifugation for $10 \mathrm{~min}$ at $4000 \mathrm{~g}$ at $4^{\circ} \mathrm{C}$. The bacterial sediment was used for genome DNA extraction using a total genome DNA extraction kit (Shanghai Sangon, Shanghai, China). All procedures were performed in a biological safety cabinet in a special laboratory. 


\section{Target gene cloning}

When first target bls gene was cloned, specific forward and reverse primers (F1: 5'-CCG GAA TTC ATG AAC CAA AGC TGT CCG AAC-3'; R1: 5'-CCG CTC GAG TCA GAC AAG CGC GGC GAT GC-3') were designed to clone the intact DNA sequence. Using $B$. suis $\mathrm{S} 2$ total genomic DNA as template, polymerase chain reaction (PCR) amplification was carried out as follows: $94^{\circ} \mathrm{C}$ for $3 \mathrm{~min} ; 35$ cycles of $94^{\circ} \mathrm{C}$ for $30 \mathrm{~s}, 53^{\circ} \mathrm{C}$ for $45 \mathrm{~s}$, and $72^{\circ} \mathrm{C}$ for $30 \mathrm{~s}$; extension at $72^{\circ} \mathrm{C}$ for $5 \mathrm{~min}$. PCR products were in-gel purified using the gel purification kit (Shanghai Sangon) following the manufacturer instructions. This was followed by ligation into the pET-28a vector (TaKaRa, Shiga, Japan) and transformation into competent DH5a cells. The positive recombinants were identified on kanamycin-containing LB plates and by PCR screening using 2 specific primers, F1 and R1. Positive clones were sequenced by Shanghai Sangon.

When the second target omp31 antigenic gene was cloned, specific forward and reverse

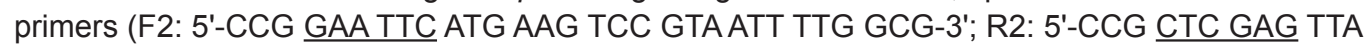
GAA CTT GTA GTT CAG-3') were designed to clone the gene intact DNA sequence. Using $B$. suis $\mathrm{S} 2$ total genomic DNA as template, PCR amplification was carried out as follows: $94^{\circ} \mathrm{C}$ for $3 \mathrm{~min} ; 35$ cycles of $94^{\circ} \mathrm{C}$ for $30 \mathrm{~s}, 57^{\circ} \mathrm{C}$ for $45 \mathrm{~s}$, and $72^{\circ} \mathrm{C}$ for $40 \mathrm{~s}$; extension at $72^{\circ} \mathrm{C}$ for $5 \mathrm{~min}$. PCR products were in-gel purified using a gel purification kit following the manufacturer instructions. This was followed by ligation into the pGEX-4T-1 vector (TaKaRa) and transformation into competent DH5 $\alpha$ cells. Positive recombinants were identified on ampicillin-containing LB plates and by PCR screening using 2 specific primers, F2 and R2. Positive clones were sequenced by Shanghai Sangon.

When the third target omp31-b/s fusion gene was cloned, 2 pairs of specific forward and reverse primers (F3: 5'-CCG GAA TTC ATG AAG TCC GTA ATT TTG GCG-3'; R3: 5'- GTT CGG ACA GCT TTG GTT CAT GAA CTT GTA GTT CAG ACC G-3' and F4: 5'-CGG TCT GAA CTA CAA GTT CAT G AA CCA AAG CTG TCC GAA C-3'; R4: 5'- CCG CTC GAG TCA GAC AAG CGC GGC GAT G -3') were designed to clone the fusion gene DNA sequence. Using $B$. suis $S 2$ total genomic DNA as template, the first PCR amplification was carried out using F3 and R3, as follows: $94{ }^{\circ} \mathrm{C}$ for $3 \mathrm{~min} ; 35$ cycles of $94^{\circ} \mathrm{C}$ for $30 \mathrm{~s}, 61^{\circ} \mathrm{C}$ for $45 \mathrm{~s}$, and $72^{\circ} \mathrm{C}$ for $45 \mathrm{~s}$; extension at $72^{\circ} \mathrm{C}$ for $5 \mathrm{~min}$. The second PCR amplification was carried out using F4 and R4, as follows: $94^{\circ} \mathrm{C}$ for $3 \mathrm{~min} ; 35$ cycles of $94^{\circ} \mathrm{C}$ for $30 \mathrm{~s}, 59^{\circ} \mathrm{C}$ for $45 \mathrm{~s}$, and $72^{\circ} \mathrm{C}$ for $40 \mathrm{~s}$; extension at $72^{\circ} \mathrm{C}$ for $5 \mathrm{~min}$. The 2 PCR products were in-gel purified using a gel purification kit (Shanghai Sangon) following the manufacturer instructions. Subsequently, $2 \mu \mathrm{L}$ purified PCR products was used as a template for the third PCR, using F3 and R4 as primers. The procedure was as follows: $94^{\circ} \mathrm{C}$ for 3 min; 35 cycles of $94^{\circ} \mathrm{C}$ for $30 \mathrm{~s}, 61^{\circ} \mathrm{C}$ for $45 \mathrm{~s}$, and $72^{\circ} \mathrm{C}$ for $60 \mathrm{~s}$; extension at $72^{\circ} \mathrm{C}$ for $10 \mathrm{~min}$. PCR products were also in-gel purified using a gel purification kit following the manufacturer instructions. This was followed by ligation into the pET-28a vector (TaKaRa) and transformation into competent DH5a cells. Positive recombinants were identified on kanamycin-containing LB plates and PCR screening using 2 specific primers, F3 and R4. Positive clones were sequenced by Shanghai Sangon. After sequencing, the 3 positive clones were stored at $-80^{\circ} \mathrm{C}$ until use.

\section{Recombinant expression, purification, and antiserum preparation}

Recombinant expression was conducted as follows. The pET-28-a expression vector carrying the target gene was transformed into competent Escherichia coli BL21(DE3) expression bacteria with kanamycin resistance for recombinant expression. Subsequent purification steps used His Bind resin chromatography (Novagen, Billerica, MA, USA). The pGEX-4T-1 expression vector 
carrying the target gene was transformed into competent E. coli BL21 expression bacteria with ampicillin resistance for recombinant expression. Subsequent purification work used Glutathione Sepharose 4B chromatography (Novagen).

Next, $3 \mathrm{~mL}$ transformants cultured overnight were transferred into $300 \mathrm{~mL}$ Luria-Bertani broth containing kanamycin or ampicillin for large-scale culture. When the $\mathrm{OD}_{600}$ value reached $0.6,0.5 \mathrm{mM}$ isopropyl $\beta$-D-1-thiogalactopyranoside was added to induce target recombinant protein expression. After culturing at $37^{\circ} \mathrm{C}$ for $3 \mathrm{~h}$, the bacteria were collected by centrifugation at $4000 \mathrm{~g}$ for $5 \mathrm{~min}$ and re-suspended in $20 \mathrm{~mL} 1 \mathrm{X}$ phosphate-buffered saline (PBS) containing $0.2 \%$ Triton $X-100$. The bacteria collected were lysed by ultrasonication. The soluble fraction was used for protein purification. The target recombinant protein was respectively purified by His Bind resin chromatography or Glutathione Sepharose 4B chromatography following the manufacturer instructions. Purified recombinant protein was stored at $-80^{\circ} \mathrm{C}$ until use.

Purified recombinant protein was used as protein antigen to produce polyclonal rabbit antiserum using a previously described method (Du et al., 2010). The His or GST tag was removed from recombinant proteins using thrombin before injection into animals. The purified recombinant protein was briefly re-isolated by SDS-PAGE. The area of the gel containing the sample band was homogenized with $1 \mathrm{~mL}$ saline and mixed with $1 \mathrm{~mL}$ complete Freund's adjuvant. The thoroughly mixed samples were subcutaneously injected into the rabbits once per week for 3 weeks. Subsequently, $100 \mu \mathrm{g}$ highly purified recombinant protein was injected without adjuvant once weekly for 6 weeks through a vein along the edge of the ear. Blood samples were collected to perform western blot analysis after the last booster.

\section{Western blot analysis}

Western blot analysis was performed to investigate the immunogenicity of 3 recombinant proteins. Proteins used for SDS-PAGE samples included recombinant rBLS, rOmp31, and rOmp31BLS. These proteins were then electrically transferred onto a nitrocellulose membrane. Proteins bands were detected using corresponding rabbits antiserum in an immunoblotting assay.

\section{Polymerization of rBLS molecule in vitro}

Reformative non-reducing SDS-PAGE was used to detect the polymerization of the rBLS molecule in vitro. Boiling and $\beta$-mercaptoethanol were used for non-reducing SDS-PAGE. For the first group, $\beta$-mercaptoethanol was not included. For the second group, boiling was not conducted. For the third group, boiling was not conducted and $\beta$-mercaptoethanol was not included. Proteins from the 3 groups were electrically transferred onto a nitrocellulose membrane at the same time. Proteins bands were detected using corresponding rabbits antiserum in an immunoblotting assay.

\section{ELISA detection of rOmp31 and rOmp31-BLS antiserum}

To estimate the immune stimulatory effects of different antigens, an ELISA assay was performed to detect the antibody titer. Briefly, ELISA 96-well plates were coated with $100 \mu \mathrm{L} 100$ $\mu \mathrm{g} / \mathrm{mL}$ rOmp31 solution or $100 \mu \mathrm{g} / \mathrm{mL}$ rOmp31-BLS solution. The antigen protein solution was diluted with $0.05 \mathrm{M}$ sodium carbonate solution, $\mathrm{pH}$ 9.6. The control sample was $100 \mu \mathrm{L} 1 \mathrm{X}$ PBS. Samples were incubated overnight at room temperature. The plates were then washed 5 times with 1X PBS containing $0.05 \%$ Tween-20 (PBST) for 3 min each time. Next, $200 \mu \mathrm{L} 10 \%$ bovine serum 
albumin in PBST was plated and incubated for $2 \mathrm{~h}$ at room temperature. ELISA was then performed using 1:1000 dilutions of either immunized rabbit serum. The plates were again washed 5 times with PBST. Next, $100 \mu \mathrm{L}$ horseradish peroxidase-conjugated goat anti-rabbit immunoglobulin G (Shanghai Sangon) (diluted 1:1000 with 1X PBS) was added to each well of the plate. The plates were again incubated for $1 \mathrm{~h}$ at room temperature. The plates were then washed 5 times with PBST. Subsequently, $100 \mu \mathrm{L}$ substrate (OPD- $\mathrm{H}_{2} \mathrm{O}_{2}$ ) was dispensed into each well. Ten minutes later, the reaction was stopped by adding $50 \mu \mathrm{L} 20 \% \mathrm{H}_{2} \mathrm{SO}_{4}$. An ELISA microplate reader was used to read the absorbance at $492 \mathrm{~nm}$. This experiment was repeated 3 times. The data obtained were statistically analyzed followed by an unpaired sample $t$-test. Significant difference was accepted at $P<0.05$. Extremely significant differences were accepted at $P<0.01$.

\section{RESULTS}

\section{cDNA sequences of bls gene and omp31 gene}

The intact cDNA sequences of the $B$. suis bls gene and omp31 gene were obtained after sequencing and assembly. Both 477-bp and a 723-bp open reading frame fragments were cloned. After BLAST online analysis, we chose 1 gene as the $B$. suis b/s gene, referred to as Bs-b/s, while the other gene was $B$. suis omp31, referred to as Bs-omp31. The open reading frame of Bs-b/s encoded 158 amino acid residues, which did not contain the signal peptide sequence (Figure 1). The open reading frame of Bs-omp31 encoded 240 amino acid residues and did not contain the signal peptide sequence (Figure 2).

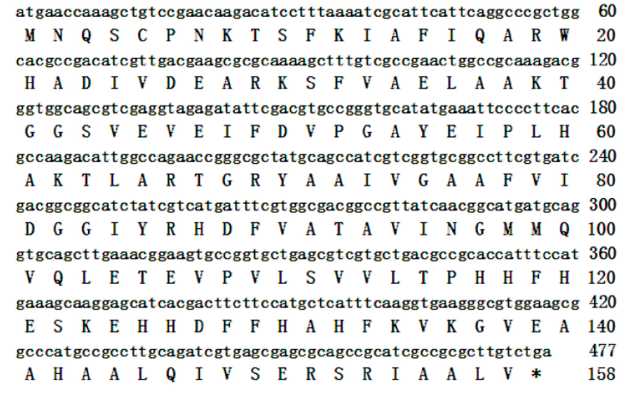

Figure 1. Nucleotide sequence of Bs-bls cDNA and the deduced amino acid sequence.

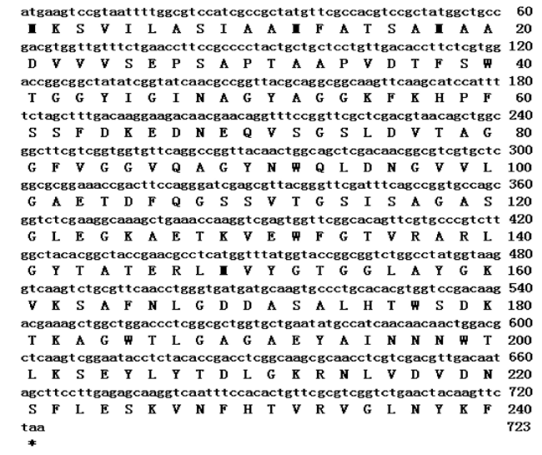

Figure 2. Nucleotide sequence of Bs-omp31 cDNA and the deduced amino acid sequence. 


\section{Recombinant expression and purification of rBs-BLS, rBs-Omp31, and rBs- Omp31-BLS}

After expression induction, recombinant $r B s-B L S$, rBs-Omp31, and rBs-Omp31-BLS were correctly expressed in the $E$. coli recombinant expression system. The theoretically predicted molecular mass of $\mathrm{rBs}$-BLS was $21 \mathrm{kDa}$, which includes the molecular mass of the His-tag (5.6 $\mathrm{kDa}$ ). The SDS-PAGE results (Figure 3 ) showed that the target band of $\mathrm{rBs}$-BLS was consistent with the theoretical value. Western blot analysis (Figure 4) revealed that this protein band was recognized by the polyclonal antibody produced by rabbit after injection with purified rBs-BLS (without His-tag). The theoretically predicted molecular mass of rBs-Omp31 was $55.3 \mathrm{kDa}$, which includes the molecular mass of the GST-tag $(25 \mathrm{kDa})$. The SDS-PAGE results (Figure $5 \mathrm{~A}$ ) showed that the target band of $r B s-O m p 31$ was consistent with the theoretical value. Western blot analysis showed that this protein band was recognized by the polyclonal antibody produced in rabbits after injection with purified rBs-BLS (without GST-tag) (Figure 5B). Additionally, the theoretically predicted molecular mass of fusion rBs-Omp31-BLS was $49.4 \mathrm{kDa}$, which includes the molecular mass of the His-tag $(5.6 \mathrm{kDa})$. The SDS-PAGE result (Figure 6A) showed that the target band of $r B s-O m p 31-B L S$ was consistent with the theoretical value. Western blot analysis (Figure 6B) showed that this protein band was recognized by the polyclonal antibody produced by rabbit after injection with purified rBs-Omp31-BLS (without His-tag).

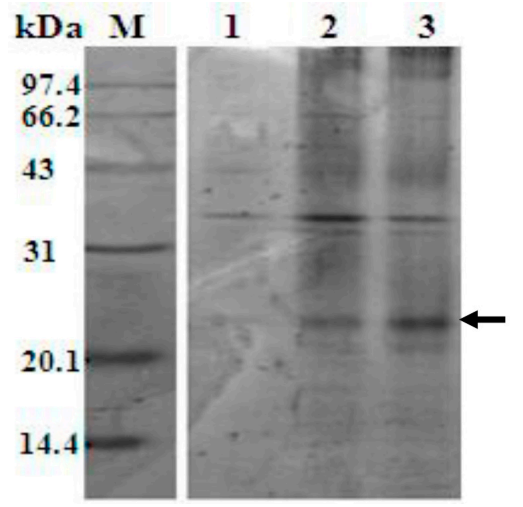

Figure 3. SDS-PAGE analysis of the recombinant expression of Bs-bls in Escherichia coli. Lane 1, total proteins of E. coli with pET-28a-Bs-bls, without induction; lanes 2 and 3, induction with 1 mM IPTG; and lane M, standard protein marker.

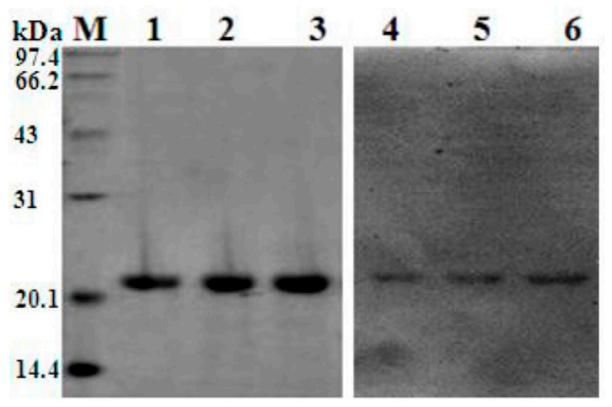

Figure 4. Western blot analysis evaluating the quality of rBs-BLS antibody. Lane $M$, standard protein marker; lanes 1 , 2 , and 3, protein lanes of rBs-BLS; lanes 4, 5, and 6, western blot lanes after immune recognition. 


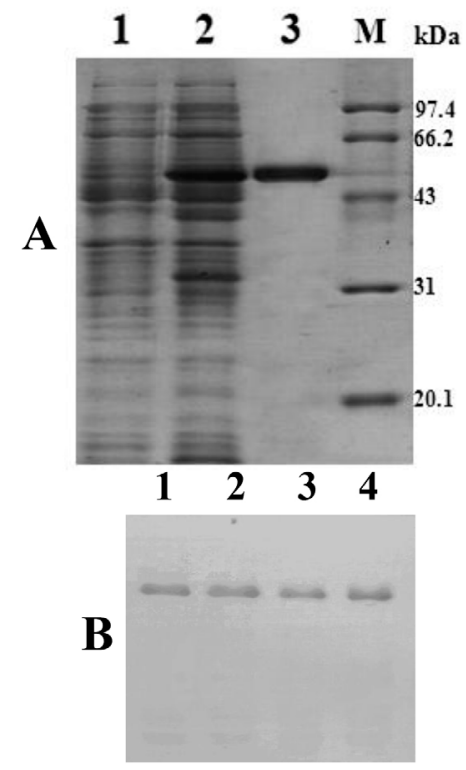

Figure 5. SDS-PAGE analysis of the recombinant expression of Bs-omp31 in Escherichia coli (A) and western blot analysis for rBs-Omp31 after corresponding antibodyrecognition (B). In Figure 5A, Lane 1, total proteins of E. coli with pGEX-4T-1-omp31, without induction; lane 2, induction with $1 \mathrm{mM} \mathrm{IPTG;} \mathrm{lane} \mathrm{3,} \mathrm{purified} \mathrm{rBs-Omp31} \mathrm{protein,} \mathrm{and} \mathrm{lane}$ $M$, standard protein marker. In Figure 5B, lanes 1, 2, and 3, western blot lanes after immune recognition.

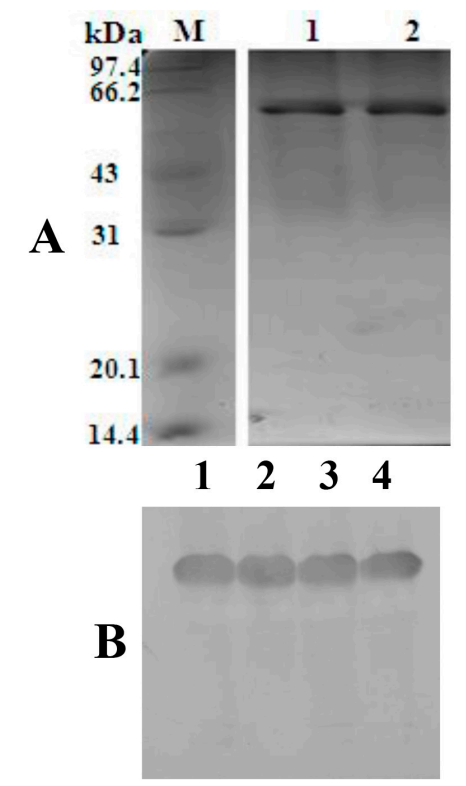

Figure 6. SDS-PAGE analysis of the recombinant expression of Bs-omp31-bls in Escherichia coli (A) and western blot analysis for rBs-Omp31-BLS after corresponding antibodyrecognition (B). In Figure 6A, lane 1, total proteins of E. coli with pET-28-a-Bs-omp31, without induction; lane 2, induction with $1 \mathrm{mM} \mathrm{IPTG;} \mathrm{lane} \mathrm{3,} \mathrm{purified} \mathrm{rOmp31-BLS} \mathrm{protein,}$ and lane $M$, standard protein marker. In Figure 6B, lanes 1, 2, 3 and 4, western blot lanes after immunerecognition. 


\section{Non-reducing SDS-PAGE results for polymerization of rBs-BLS molecule in vitro}

Reformative non-reducing SDS-PAGE was used to detect the polymerization of $r B s-B L S$ in vitro. When the first group was assayed, $\beta$-mercaptoethanol was not added to the sample. For the second group, boiling was not conducted. For the third group, both boiling and $\beta$-mercaptoethanol were eliminated. After non-reducing SDS-PAGE of proteins in the 3 groups, the proteins were electrically transferred onto a nitrocellulose membrane. Bands were detected using corresponding rabbit antiserum against rBs-BLS (without His-tag) in an immunoblotting assay. Finally, reformative non-reducing SDS-PAGE showed that $r B s$-BLS existed in different forms, including as a dimer and pentamer (Figure 7). When $\beta$-mercaptoethanol was not added, proteins mainly remained as monomers. When boiling was not conducted, proteins also mainly remained as monomers. We speculated that most of the proteins were denatured under this condition. However, monomers decreased and dimer formation increased when both boiling and $\beta$-mercaptoethanol were eliminated, and pentamers began to appear (Figure 7). Some samples proteins may not have been denatured under this condition, and were thus able to polymerize.

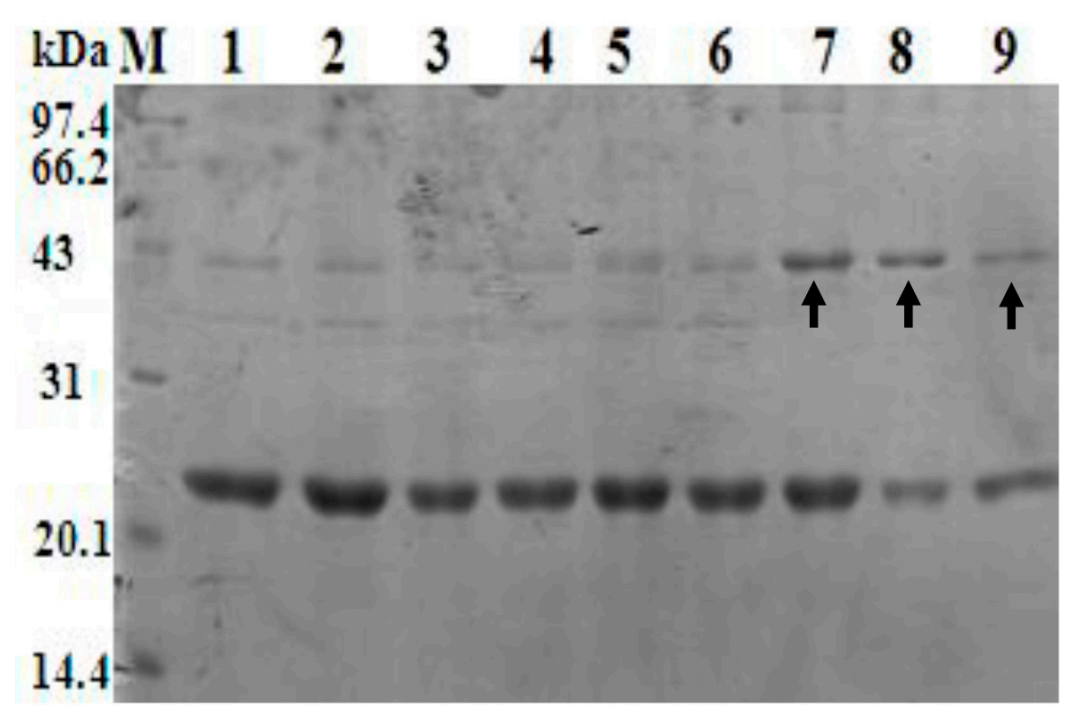

Figure 7. Results of the reformative non-reducing SDS-PAGE for polymerization analysis of rBLS molecule in vitro. Lane $M$, standard protein marker; lanes 1, 2, and 3, protein samples treated without the $\beta$-mercaptoethanol; lanes 4 , 5 , and 6 , protein samples treated without boiling; lanes $\beta$-mercaptoethanol.

\section{ELISA results of antibody titer assessment}

To assess BLS aggregation for antigen proteins molecules during immune stimulation, ELISA was performed to detect the antibody titer. The results showed that the intact rOmp31-BLS fusion protein could stimulate much higher antibody levels than rOmp31 or rBLS protein. The absorbance value of rOmp31-BLS was nearly 6-fold higher than that of rBLS and 5-fold higher than that of rOmp31 (Figure 8). Thus, the antibody titer of antiserum against rOmp31-BLS fusion protein was clearly higher than the antibody titer of antiserum against rOmp31 protein or rBLS protein. 


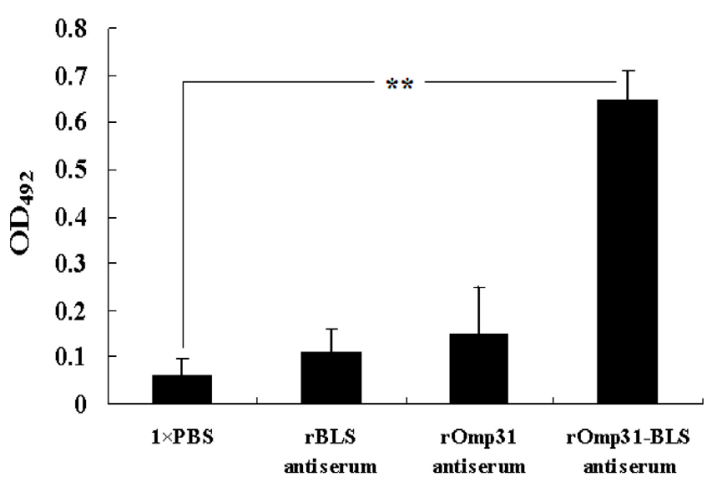

Figure 8. ELISA results for antibody titer assessment. The asterisks indicate extremely significant differences ${ }^{* *} \mathrm{P}<$ 0.01 ) from the control. Error bars represent \pm SD of 3 independent assays.

\section{DISCUSSION}

During the evolutionary process, bacteria that have established a chronic infection status in their hosts have developed a wide range of strategies to defend against and evade the host innate and adaptive immunity responses. Brucella is an intracellular bacteria and plays a direct pathogenic role in brucellosis. Although previous studies have aimed at improving brucellosis diagnosis techniques, the evaluation of alternative means of disease prevention have not been thoroughly examined. Subunit vaccines such as recombinant proteins are promising candidates because they are much safer, not infectious, and cannot revert to virulence. These problems are often observed in live attenuated vaccines. Proper selection of an immunogen would avoid a cross-reaction during diagnosis. Brucella Omps are ideal immunogens for subunit vaccine preparation. The rOmp31 from $B$. melitensis was found to stimulate antiserum production in sheep and ram (Estein et al., 2004). Immunization of animals with $B$. ovis encoding for rOmp31 was reported to induce acceptable protection against B. ovis infection in immunized mice (Díaz et al., 2013). Additionally, through the interaction with immunized rabbit serum, rOmp31 also reacted much more strongly than pre-immunized rabbit serum according to ELISA results (Ghasemi et al., 2013). These data suggest that rOmp31 is a good candidate for subunit vaccine against Brucella. In the present study, the $B$. suis omp31 gene was cloned; this gene was $723 \mathrm{bp}$ and did not contain a signal peptide sequence (Figure 2). After cloning into the E. coli pGEX-4T-1 expression vector, the $B$. suis omp31 gene was successfully expressed. The predicted molecular mass of rBs-Omp31 was $55.3 \mathrm{kDa}$, which included the molecular mass of the GST-tag (25 kDa) (Figure 5A). This rBs-Omp31 protein successfully stimulated rabbits to produce antiserum. Western blotting analysis showed that the $\mathrm{rBs}-\mathrm{Omp} 31$ protein was specifically recognized by the corresponding rabbit antiserum (Figure 5B).

In addition, the b/s gene has shown favorable immune-stimulation function. The incomplete fusion BLS-Omp31 protein vaccine elicited immune activation, which may be useful for effectively controlling canine brucellosis (Clausse et al., 2013). However, an incomplete BLS molecule was previously fused with an incomplete Omp31 molecule. Thus, we cloned the intact $B$. suis b/s gene, which was $477 \mathrm{bp}$ without the signal peptide sequence (Figure 1). After cloning into the E. coli pET-28-a expression vector, intact $B$. suis b/s gene was successfully expressed. The predicted molecular mass of rBs-BLS was $21 \mathrm{kDa}$, which included the molecular mass of His-tag (5.6 kDa) (Figure 3). This rBs-BLS protein successfully stimulated rabbits to produce antiserum. Western blotting analysis showed that the $\mathrm{rBs}$-BLS protein was specifically recognized by the corresponding 
rabbit antiserum (Figure 4). To study the polymerization of endogenous BLS, non-reducing SDSPAGE was performed. The results showed that monomer formation rBLS was decreased and dimer formation was increased when both boiling and $\beta$-mercaptoethanol were not included. Additionally, pentamers began to form (Figure 7). These results indicate that in Brucella, endogenous BLS can exist in at least 3 forms, that is, monomer, dimmer, and pentamer. The results also confirmed that the endogenous BLS molecule exerts its function in polymer form.

We also conducted a protein fusion assay in which we structured an omp31-b/s fusion expression vector. After cloning into the E. coli pET-28-a expression vector, the omp31-b/s fusion gene was successfully expressed. The predicted molecular mass of rBs-BLS was $49.4 \mathrm{kDa}$, which included the molecular mass of the His-tag (5.6 kDa) (Figure 6A). This Omp31-BLS fusion protein successfully stimulated the rabbit to produce antiserum. Western blotting analysis showed that the rOmp31-BLS fusion protein was specifically recognized by the corresponding rabbit antiserum (Figure 6B). To further examine the immunogenicity of the rOmp31-BLS fusion protein, ELISA was performed. The results showed that the intact rOmp31-BLS fusion protein could stimulate the production of much higher antibody levels than did the rOmp31 or rBLS proteins alone. According to the results of the $t$-test for the assay data, the antibody titer of antiserum against the rOmp31BLS fusion protein was clearly higher than the antibody titer of antiserum against the rOmp31 protein or rBLS protein (Figure 8). rOmp31-BLS fusion showed an enhanced immune-stimulation effect, possibly because of the BLS molecule polymerizing function. After injection into rabbits, the rOmp31-BLS fusion protein may have been stimulated to form a polymer.

Omp31 showed positive results as a subunit vaccine candidate. This molecule stimulated the host to produce acceptable antiserum. After fusion with BLS, the immunogenicity of Omp31 was increased. The rOmp31-BLS fusion protein immunogenicity was related not only to immune stimulation by Omp31 but also to the polymerizing function of BLS.

\section{Conflicts of interest}

The authors declare no conflict of interest.

\section{ACKNOWLEDGMENTS}

Research supported by the National Natural Science Foundation of China (Grant \#31460698).

\section{REFERENCES}

Avila-Calderón ED, Lopez-Merino A, Sriranganathan N, Boyle SM, et al. (2013). A history of the development of Brucella vaccines. Biomed. Res. Int. 2013: 743509-743516.

Cassataro J, Estein SM, Pasquevich KA, Velikovsky CA, et al. (2005a). Vaccination with the recombinant Brucella outer membrane protein 31 or a derived 27-amino-acid synthetic peptide elicits a CD4+ T helper 1 response that protects against Brucella melitensis infection. Infect. Immun. 12: 8079-8088.

Cassataro J, Velikovsky CA, de la Barrera S, Estein SM, et al. (2005b). A DNA vaccine coding for the Brucella outer membrane protein 31 confers protection against $B$. melitensis and $B$. ovis infection by eliciting a specific cytotoxic response. Infect. Immun. 10: 6537-6546.

Chen S, Zhang H, Liu X, Wang W, et al. (2014). Increasing threat of brucellosis to low-risk persons in urban settings, China. Emerg. Infect. Dis. 1: 126-130.

Clausse M, Díaz AG, Ghersi G, Zylberman V, et al. (2013). The vaccine candidate BLS-Omp31 protects mice against Brucella canis infection. Vaccine 51: 6129-6135. 
Dean AS, Crump L, Greter H, Schelling E, et al. (2012). Global burden of human brucellosis: a systematic review of disease frequency. PLoS Negl. Trop. Dis. 10: e1865.

Denisov AA, Karpova OM, Korobovtseva YS, Salmakov KM, et al. (2010). Development and characterization of a modified Komarov's bullet for ballistic delivery of live Brucella abortus strains 82 and 19 to cattle and bison. Vaccine 5: F23-F30.

Díaz AG, Clausse M, Paolicchi FA, Fiorentino MA, et al. (2013). Immune response and serum bactericidal activity against Brucella ovis elicited using a short immunization schedule with the polymeric antigen BLSOmp31 in rams. Vet. Immunol. Immunopathol. 1-2: 36-41.

Du ZQ, Li XC, Wang ZH, Zhao XF, et al. (2010). A single WAP domain (SWD)-containing protein with antipathogenic relevance in red swamp crayfish, Procambarus clarkii. Fish Shellfish Immunol. 1: 134-142.

Estein SM, Cheves PC, Fiorentino MA, Cassataro J, et al. (2004). Immunogenicity of recombinant Omp31 from Brucella melitensis in rams and serum bactericidal activity against B. ovis. Vet. Microbiol. 3-4: 203-213.

Estein SM, Fiorentino MA, Paolicchi FA, Clausse M, et al. (2009). The polymeric antigen BLSOmp31 confers protection against Brucella ovis infection in rams. Vaccine 48: 6704-6711.

Ghasemi A, Salari MH, Zarnani AH, Pourmand MR, et al. (2013). Immune reactivity of Brucella melitensis-vaccinated rabbit serum with recombinant Omp31 and DnaK proteins. Iran J. Microbiol. 1: 19-23.

Godfroid J, Nielsen K and Saegerman C (2010). Diagnosis of Brucellosis in livestock and wildlife. Croat. Med. J. 4: $296-305$.

Gomez G, Pei J, Mwangi W, Adams LG, et al. (2013). Immunogenic and invasive properties of Brucella melitensis 16M outer membrane protein vaccine candidates identified via a reverse vaccinology approach. PLoS One 3: e59751.

Kaushik P, Singh DK, Kumar SV, Tiwari AK, et al. (2010). Protection of mice against Brucella abortus 544 challenge by vaccination with recombinant OMP28 adjuvanted with CpG oligonucleotides. Vet. Res. Commun. 2: 119-132.

Luo DY, Li P, Xing L, Zhao GY, et al. (2006). DNA vaccine encoding L7/L12-P39 of Brucella abortus induces protective immunity in BALB/c mice. Chin. Med. J. (Engl.) 4: 331-334.

Mermer S, Sipahi OR, Aydemir S, Tasbakan M, et al. (2013). Brucella melitensis shunt infection. Neurol. India 6: 670-671.

Miraglia MC, Scian R, Samartino CG, Barrionuevo P, et al. (2013). Brucella abortus induces TNF-a-dependent astroglial MMP9 secretion through mitogen-activated protein kinases. J. Neuroinflammation 12: 10-47.

Muñoz PM, Estevan M, Marín CM, Jesús De Miguel M, et al. (2006). Brucella outer membrane complex-loaded microparticles as a vaccine against Brucella ovis in rams. Vaccine 11: 1897-1905.

Pollak CN, Delpino MV, Fossati CA and Baldi PC (2012). Outer membrane vesicles from Brucella abortus promote bacterial internalization by human monocytes and modulate their innate immune response. PLoS One 11: e50214.

Schurig GG, Sriranganathan N and Corbel MJ (2002). Brucellosis vaccines: past, present and future. Vet. Microbiol. 1-4: 479496.

Yang X, Skyberg JA, Cao L, Clapp B, et al. (2013). Progress in Brucella vaccine development. Front. Biol. (Beijing) 1: 60-77.

Yüksekkaya S, Aras Z and Uçan US (2013). Investigation of Brucella canis seroprevalence in Brucellosis suspected cases. Mikrobiyol. Bul. 1: 152-157. 